\title{
Altered dopamine levels induced by the parasite Profilicollis antarcticus on its intermediate host, the crab Hemigrapsus crenulatus
}

\author{
JOSÉ MIGUEL ROJAS and F. PATRICIO OJEDA ${ }^{1}$
}

Departamento de Ecología \& Center for Advance Studies in Ecology \& Biodiversity, Pontificia Universidad Católica de Chile

\begin{abstract}
A serotonergic pathway is apparently involved in parasite-host interactions. Previous studies conducted in our laboratory showed increased rates in oxygen consumption and alterations in body posture in the crab Hemigrapsus crenulatus parasitized by the acanthocephalan, Profilicollis antarcticus. Such changes may be related to the functions described for biogenic amines in crustaceans. During the infective stage the acanthocephalans live freely in the hemocelomic cavity, suggesting that the possible alteration induced by biogenic amines may be related to their neurohormonal function in crustaceans. To test whether the presence of $P$. antarcticus produced neurohormonal changes in its intermediate host, $H$. crenulatus, we analyzed serotonin and dopamine levels in the host using HPLC with electrochemical detection. Two groups of 11 female crabs were studied; one group was artificially inoculated with two cystacanths while the other was used as the control. Our results show a dramatic increase in hemolymph dopamine, but not serotonin in $H$. crenulatus parasitized by the acanthocephalan $P$. antarcticus. Our results, along with those reported by Maynard (1996), suggest a parasite-specific strategy involved in the behavior alteration caused by the acanthocephalans on their intermediate host. The use of a biogenic amine as a mechanism of interaction by the parasites gives them an endless number of alternative potential actions on their intermediate hosts.
\end{abstract}

Key terms: acanthocephalans, biogenic amines, HPLC, parasite-host interaction, parasite transmission.

\section{INTRODUCTION}

Parasites with complex life cycles involving several hosts are faced with problems of how to spread from one host to the next. The ability of parasites to induce alterations in their intermediate hosts has frequently been related to a type of adaptive strategy that would allow them to complete their life cycles (Holmes and Bethel, 1972; Camp and Huizinga, 1979; Dobson, 1988; Combes, 1991; Haye and Ojeda, 1998). Questions regarding the mechanisms through which the infected intermediate hosts change their behavior have received little attention in the literature. Most of the existent studies have focused on quantifying the morphological and behavioral changes induced by parasites (Thompson and Kavaliers, 1994; Lafferty and Morris, 1996). These alterations have been attributed to a direct mechanical effect at the site of infection (Moore, 1984b; Poulin, 1995) and/or active interference in host neuroendocrine signaling systems (Adamo and Shoemaker, 2000; Overli et al., 2001; Adamo, 2002; Helluy and Thomas, 2003).

In crustaceans, several studies have reported changes in biogenic amino levels in individuals infected with Acanthocephalan (cystacanth) and Platyhelminthes (metacercaria) larvae (Helluy and Holmes, 1990; Maynard et al., 1996; Adamo, 2002; Helluy and Thomas 2003). Both kinds of parasites use different strategies of infection;

Corresponding Author: F. Patricio Ojeda, Departamento de Ecología y Centro para Estudios Avanzados en Ecología y la Biodiversidad, Pontificia Universidad Católica de Chile, Casilla 114-D Santiago, 6513677, Chile, Telephone: (56-2) 686-2729, Fax: (56-2) 686-2621, E-mail: pojeda@bio.puc.cl 
Platyhelminth larvae encyst into the nervous system, causing physical harm to their victim. The cystacanth lives freely in the host's hemocoel without ever coming into contact with the host's central nervous system (CNS) (Maynard et al., 1996; Overli et al., 2001). Therefore, it has been suggested that any interference of an acanthocephalan on the neuroendocrine system of an intermediate host may be under biochemical control.

Uninfected gammarids with serotonin and octopamine injected into the hemocoel show similar body attitudes to crustaceans (i.e. Gammarus lacustris) infected by the acanthocephalan, Polymorphus paradoxus (Helluy and Holmes, 1990). In the same host-parasite system, Maynard et al. (1996) showed an increase in serotonin-like immunoreactivity in the CNS of infected gammarids, suggesting either a greater number of varicosities (potential release sites) or an increase in the amount of stored serotonin. As a consequence, researchers have suggested the existence of a chemical interaction associated with a serotonergic pathway between infected individuals and this type of parasite (Helluy and Holmes, 1990; Maynard et al., 1996).

Monoamines dopamine (DA), serotonin (5-HT) and octopamine are recognized as important substances in modulating behavior in vertebrates and invertebrates (e.g. neurotransmitters, neuromodulators and neurohormones). These substances perform specific roles in synaptic transmissions and induce changes in the electrical activity of neurons. At the molecular level, their activities include modulation of ion channels, protein synthesis, and enzyme activity, etc. (Livingstone et al., 1980; Walker et al., 1996; Libersat and Pflueger, 2004). It is generally believed that the release of specific neuromodulators activates specific neuronal circuits that underlie particular behaviors, therefore it has been suggested that behavior per se is the result of a coordinated action of monoamines, as in Sombati and Hoyle's "Orchestration behavior hypothesis" (1984), (see also Livingstone et al., 1980; Kravitz, 1988; Flamm and Harris-Warrick, 1986; Rajashekhar and Wilkens, 1991; Sneddon et al., 2000; Libersat and Pflueger, 2004; Huber 2005).

The most commonly reported consequences of parasites during their infective stage in intermediate hosts are changes in response to external stimuli due to neurological damage, increased conspicuity resulting from modified pigmentation and/or behavior, and castration (Camp and Huizinga, 1979; Oetinger and Nichol, 1982; Moore, 1984a; Moore and Gotelli, 1992; Moore et al., 1994; Poulin, 1995; Bakker et al., 1997; Seppälä et al., 2004). Specific behavioral alterations include changes in activity, photoreaction, escape behavior, substrate color choice and vertical distribution (Moore, 1984a,b; Poulin, 1994). The display of any of these behaviors implies a coordinated action of the motor and physiological systems of the host, where the actions of different monoamine pathways are implicit. It is therefore unlikely that only one biochemical pathway (e.g. serotonin) is involved in the host-parasite interaction.

The acanthocephalan, Profilicollis antarcticus, uses the estuarine crab Hemigrapsus crenulatus as its intermediate host, and the gull, Larus dominicanus as its definitive host. Previous studies conducted in our laboratory showed that crabs infected with cystacanths exhibited higher metabolic rates and activity levels than non-parasitized crabs (Haye and Ojeda, 1998). In decapods, studies of neurohormonal control of behavior have shown that the level of aggressiveness in individuals is related to concentrations of circulating dopamine (Sneddon et al., 2000). Furthermore, the control of heartbeat frequency and strength are fundamentally associated with the action of the serotoninergic pathway, while the maintenance and rhythm of ventilatory patterns are controlled by a dopaminergic pathway (Rajashekhar and Wilkens, 1991; Ayali et al., 1998; Harris-Warrick et al., 1998). As a consequence of the complexity of these pathways, the above-mentioned interaction between a host and its parasite could be linked with any one or more aminergic pathways.

The primary goal of this study was to determine whether the presence of 
cystacanths of the acanthocephalan Profilicollis antarcticus could cause alterations in the levels of hemolymph serotonin and/or dopamine in its intermediate host, the crab Hemigrapsus crenulatus. With this objective in mind we evaluated the levels of serotonin and dopamine circulating into the hemolymph following the standard methodology for catecolaminas determination by high pressure liquid chromatograph (HPLC).

\section{MATERIALS AND METHODS}

\section{Crustacean host}

Crabs were manually collected from the Lenga Estuary $\left(36^{\circ} 45^{\prime} \mathrm{S}, 73^{\circ} 10^{\prime} \mathrm{W}\right)$ in 1995 and transported to the laboratory at the Universidad de la Santísima Concepción. This estuary is located within the nature reserve in Hualpén Peninsula, in the VIII Region of south-central Chile. Given that it is not possible to distinguish between infected and uninfected crabs, one group of randomly assigned individuals were artificially inoculated with cystacanths. The inoculation was carried out by lifting the posterior region of the cephalothorax and depositing two cystacanths into the hemocoel cavity using tweezers. The cystacanths were previously extracted from the dorsal part of the hemocoel cavity of live crabs. The second group of experimental crabs was used as a procedural control. Following inoculation and prior to experiments, both treatment groups were acclimatized in aerated aquariums for 35 days at $16.5^{\circ} \mathrm{C}$, with a salinity of $20 \mathrm{ppm}$ (typical of the estuary), and a 12: 12 light dark cycle.

\section{Hemolymph sample collection}

Hemolymph samples (100 to $300 \mu \mathrm{l}$ ) were collected from live crabs at room temperature using a tuberculin syringe. The syringe was inserted through the gap in the posterior region of the exoskeleton into the hemocoel cavity, where the hemolymph was collected. These samples were placed in eppendorf tubes and frozen at $-40^{\circ} \mathrm{C}$ until the assays were performed. The tubes were centrifuged at $200 \mathrm{xg}$ for 10 minutes to obtain samples free of tissue and cellular residues.

\section{Estimation of serotonin and dopamine levels}

Circulating levels of Serotonin and dopamine were measured by high-pressure liquid chromatography with electrochemical detection, as described by Kumar et al. (1990). From the previously centrifuged samples, one 100-microliter aliquot of supernatant from each individual was transferred to microcentrifuge tubes containing $20 \mu \mathrm{l}$ of $3.4 \mathrm{M}$ perchloric acid $\left(\mathrm{HClO}_{4}\right)$. These samples were mechanically homogenized for 30 to $40 \mathrm{sec}$ using a motor driven homogenizer equipped with a Teflon pestle. Next, the samples were left to rest for $10 \mathrm{~min}$ at $4^{\circ} \mathrm{C}$, and then centrifuged at 9000 $\mathrm{xg}$ for $10 \mathrm{~min}$. The supernatant was diluted with mobile phase, and biogenic amine quantification was carried out by injecting $20 \mu \mathrm{l}$ from each sample of crab hemolymph into a chromatograph coupled to an electrochemical detector. The mobile phase contained $0.1 \mathrm{M}$ acetonitrile, $0.8 \mathrm{mM}$ EDTA and $10 \%$ methanol at $\mathrm{pH} 4.6$.

Serotonin and dopamine standards (grade HPLC, Sigma Chemical Co.) were used to calibrate the system. The standards were prepared in $0.4 \mathrm{M} \mathrm{HClO}_{4}$ and $0.4 \mathrm{mM}$ sodium metabisulphite $\left(\mathrm{Na}_{2} \mathrm{~S}_{2} \mathrm{O}_{5}\right)$. The HPLC system consisted of a Waters 501 pump with a Waters U6K injector (Waters Associates, Milford, MA), a Beckman C18 column (5 $\mu \mathrm{m}$ particle diameter, $4.6 \mathrm{~mm} \times 25 \mathrm{~cm})$, and a model LC 1260 electrochemical detector (ICI Instruments, Australia). The applied chromatography conditions were a flow rate of $1.0 \mathrm{ml} / \mathrm{min}$, working potential +700 mvolt v/s electrode $\mathrm{Ag} / \mathrm{AgCl}$ for 5-HT and DA at ambient temperature. Under these experimental conditions, the retention times were $6.5 \pm 0.3 \mathrm{~min}$ for serotonin and $3.9 \pm 0.2$ min for dopamine.

Standards and samples were injected alternately for identification and quantification analysis. The identification of each peak was achieved by comparing retention times and spiking. Biogenic amine 
contents were determined by comparing peak areas with known external standards.

\section{Parasite load}

Given that parasites live freely within the hemocoel cavity, it was not possible to determine the presence of cystacanths prior to artificial inoculation. Therefore, after the samples were obtained, crabs were dissected under a stereomicroscope to determine the presence and number of parasites in the infected crab group $(n=11)$ and control group $(n=11)$. The experimental groups confirmed upon completion of this procedure. Only female crabs were used because of the low number of male crabs captured.

\section{Data analysis}

The results are expressed as mean \pm standard error. A non-parametric MannWhitney $U$ test was used to determine whether there were significant differences (at the 5\% level) between treatments (Siegel and Castellan, 1988).

\section{RESULTS}

HPLC procedure was used to determine circulating levels of serotonin and dopamine in the hemolymph. Crabs that were artificially infected with cystacanths showed significantly greater mass specific dopamine levels than control individuals $(n=11$ for both groups; Table I). Serotonin was not detected in either of the treatment groups. No significant differences in body mass were found between the two groups (Table I). The same number of parasites were found within individuals of the infected group $(n=2)$.

\section{DISCUSSION}

Our results indicate an increase in the levels of circulating dopamine in individuals of Hemigrapsus crenulatus parasitized by the acanthocephalan, Profilicollis antarcticus. Based on the functions described for dopamine (Kravitz, et al., 1980; Miller et al., 1984; Beltz and Kravitz, 1986; Flamm and Harris-Warrick, 1986; Haye and Ojeda, 1998; Rajashekhar and Wilkens, 1991) altered respiratory frequencies and body postures could be a consequence of the significantly higher levels of circulating dopamine in parasitized crabs. Our results suggest a dopaminergic pathway involved in the mechanism that induces alterations in the intermediate host of the parasite $P$. antarcticus.

Unfortunately, the literature is surprisingly deficient in basic data or absolute concentration values of circulating monoamines in invertebrates that would be useful for assessing the veracity and accuracy of our results. Estimations made with HPLC ED (electrochemical detection) indicate the absence of circulating dopamine and the predominance of octopamine $(2.2 \mathrm{ng}$ $/ \mathrm{ml}$ ) in the crayfish Pacifastacus lenusculus (Elofsson et al., 1982). Furthermore, in a euryhaline crab (Eriocheir sinensis) dopamine concentrations were $0.0022 \mathrm{pg} / \mathrm{ml}$ 0.0017 , with a maximum increase of $460 \%$ under conditions of ionic stress (Péquéux et al., 2002). In contrast, the crab Carcinus means presented appreciably lower circulating dopamine concentrations of 0.0008 to $0.0015 \mathrm{~g} / \mathrm{ml}$ (Sneddon et al., 2000). In addition, circulating monoamine concentrations may present high variability with an extreme example occurring in the hemolymph of the silkworm, Bombyx mori, where different authors have registered very dissimilar magnitudes of dopamine for similar ontogenic stages $\left(6.5 \times 10^{-5}\right.$ to 5.8 $\mathrm{x} 10^{-4} \mathrm{~g} / \mathrm{ml}$, Noguchi and Hayakawa, 2001; $0.0161 \pm 0.0018 \mathrm{~g} / \mathrm{ml}$ to $0.436 \pm 0.30 \mathrm{~g} / \mathrm{ml}$, Takeda et al., 1991).

It was not possible to distinguish the biochemical origin of changes in the levels of circulating dopamine from this study. Moreover, the presence of enzymes acting in the metabolic pathway of dopamine, which has been documented in the hemolymph of insects, indicates that the dopamine metabolic pathway is present within the hemolymph itself (Takeda et al., 1991). Therefore, the free-living condition of cystacanths in the hemocoelomic cavity of the intermediate host may be interpreted 
as the most direct way of altering the dopamine metabolic pathway. The alteration of dopamine levels in the hemolymph system implies that there is a generalized effect of the parasite on the body of its intermediate host, rather than an effect at the nerve ganglion level. Thus, the observed increase in activity and metabolic rate for this host-parasite system (Haye and Ojeda, 1998) could be a consequence of the higher metabolic costs of maintenance for the host, linked to the synthesis of monoamines and/or the physiological consequences of their bio-availability. This altered physiological condition is beneficial for the parasites, considering that their final goal is to increase transmission by increasing the probability of predation on its intermediate the host (the crab) by its definitive host (the gull).

The absence of circulating serotonin in both inoculated and control crabs is consistent with what has been observed in several invertebrate species (Takeda et al., 1991; Awad et al., 1997). In behavioral terms, the circulating levels of serotonin and some complex interactions with other amines, such as dopamine and octopamine, have usually been associated with dominance behavior in male shore crabs (Kravitz, 2000; Sneddon et al., 2000). These observations are coherent with the reduction in the individual's competitive ability for females, which has been described for male crabs infected by acanthocephalan parasites (Howard and Minchella, 1990; Read, 1990; Bollache et al., 2001). On other hand, in females castration is recognized as one of the principal consequences of infection by acanthocephalan parasites (Moore, 1984b). Latham and Poulin (2002), working with the same parasite-host system described here, showed the lack of a parasite effect on female fecundity and increased mortality in larger crabs due to an apparent active manipulation by the parasite. Both of these consequences of parasitism involve an increase in the conspicuousness of the host. However, the lack of knowledge of the origin of the castration by the acanthocephalan parasite prevents us from engaging in a more profound discussion of the implications of our results on the parasite-host relationship. The complex and broad range of actions by monoamines only increases the challenge for investigators attempting to discover more about the mechanisms of interaction between parasites and hosts.

Our results, along with those reported by Helluy and Holmes (1990) and Maynard et al. (1996) allow us to consider specific amine interactions between parasites and their host. The presence of biogenic amines in the mechanism through which acanthocephalan parasites produce behavioral alterations could indicate an

Mass specific concentration of circulating dopamine levels in the hemolymph of inoculated and control crabs. ( $\mathrm{n}=11$, both groups), and mean body weight of each experimental group. Values are expressed as mean 2 standard errors (S.E.).

\begin{tabular}{lcc}
\hline & Dopamine Concentration $(\mu \mathrm{g} / \mathrm{ml} / \mathrm{g})(\mathrm{mean} \pm 2$ S.E. $)$ & Body Weight $(\mathrm{g})(\mathrm{mean} \pm 2$ S.E.) \\
\hline Infected crabs & $0.324 \pm 0,12$ & $4.68 \pm 0.33$ \\
Non- infected crabs & $0.126 \pm 0.24$ & $4.39 \pm 0.32$ \\
Mann-Whitney U & 8.5 & - \\
p (two tails) & 0.0006 & - \\
t- Test & - & 1.13 \\
p (two tails) & - & 0.271
\end{tabular}


endless number of alternative potential actions on the hosts, given the extensive range of action of this substance on the physiology of crustaceans (Florey and Rathmayer, 1978; Livingstone et al., 1980; Miller et al., 1984; Beltz and Kravitz, 1986; Flamm and Harris-Warrick, 1986; Kravitz, 1988; Paztor and Macmillan, 1990; Rajashekhar and Wilkens, 1991; Fingerman, 1997). Thus, this substance may be responsible for the divergent behavioral changes observed in closely related species (Moore and Gottelli, 1996).

The scant knowledge of the biochemistry of acanthocephalan parasites and the interactions between behavior and physiology hinder our understanding of the physiological basis of the alterations observed in intermediate hosts. Therefore, it is not clear whether the observed alterations in intermediate hosts have an adaptive value for the transfer of the parasite or are a type of defensive response by the host caused by the presence of the parasite.

Acanthocephalans form a clearly defined group of parasitic organisms that do not appear to have close phylogenetic relationships with any other phylum. Adult acanthocephalans have only been reported in vertebrates that feed on their intermediate arthropod host, where they develop to a stage called the cystacanth, which can infest vertebrates (Baer, 1967; Moore, 1984b). Given the widespread ability of acanthocephalans to produce similar behavioral alterations in a variety of intermediate hosts, Moore (1984a) hypothesized that this ability of behavioral alteration was present in the common ancestor of acanthocephalans. It can be said that the four genera of acanthocephalans common to both marine and freshwater teleosts have a very generalized type of anatomy and are in no way specialized (Baer, 1967). Based on the above and given the fact that the biochemical traits of organisms are highly conserved (Futuyma, 1979), it is not surprising to find that the mechanism through which the parasites alter the behavior of the intermediate host is also a highly conserved biochemical process.

\section{ACKNOWLEDGEMENTS}

We thank P. Haye, A. Muñoz, M. GeorgeNascimento, and P. Neill for helpful comments. The authors would also like to thank K. Gysling, N. Inestrosa and R. Iturriaga for reviewing methodology and comments on this manuscript. Finally we thank E. Aranda for his valuable help in laboratory analysis. This research was supported by FONDECYT grant 1930420 and FONDAP 1501-0001 (Program 5) to F.P.O.

\section{REFERENCES}

ADAMO SA, SHOEMAKER KL (2000) Effects of parasitism on the octopamine content of the central nervous system of Manduca sexta: a possible mechanism underlying host behavioral change. Can J Zool 78(9): 1580-1587

ADAMO SA (2002) Modulating the modulators: parasites, neuromedulators and the host behavioral change. Brain Behav Evol. 60: 371-377

AYALI AB, JOHNSON R, HARRIS-WARRICK RM (1998) Dopamine modulates graded and spike evoked synaptic inhibition independently at single synapses in the pyloric network of the lobster. J Neurophysiol 79: 2063-2069

AWAD EW, AMIRI MH, STEPHEN RS (1997) Developmental changes in amine levels in the central nervous system and hemolymph of the eastern death's head hawk moth, Acherontia styx (Lepidoptera: Sphingidae). Comp Biochem Physiol 116C: 219-225

BAER JG (1967) Ecology of Animal Parasites. 5 ${ }^{\text {th }}$ ed. Urbana, IL: University of Illinois Press

BAKKER CM, MAZZI D, ZALA S (1997) Parasiteinduced changes in behavior and color make Gammarus pulex more prone to fish predation. Ecol 78: 1098-1104

BELTZ BS, KRAVITZ EA (1986) Aminergic and peptidergic neuromodulation in crustacea. J Exp Biol 124: $115-141$

BOLLACHE L, GAMBADE G, CÉZILLY (2001) The effects of two acanthocephalan parasites, Pomphorhynchus laevis and Polymorphus minutus, on pairing success in male Gammarus pulex (Crustacea: Amphipoda) Behav Ecol Sociobiol 49: 296-303

CAMP JW, HUIZINGA HW (1979) Altered color, behavior and predation susceptibility of the isopod Asellus intermedius infected with Acanthocephalus dirus $\mathrm{J}$ Parasitol 65: 667-669

COMBES C (1991) Ethological aspects of parasite transmission. Am Nat 138: 866-880

DOBSON AP (1988) The population biology of parasite induced changes in host behavior. Q Rev Biol 63: 139163

ELOFSSON R, LAXMYR L, ROSENGREN E, HANSSON $\mathrm{CH}$ (1982) Identification and quantitative measurements of biogenic amines and DOPA in the central nervous system and hemolymph of the crayfish Pacifastacus leniusculus (crustacean). Comp Biochem Physiol 71C (2): 195-201 
FINGERMAN M (1997) Crustacean endocrinology. A retrospective, prospective and introspective analysis. Physiol Zool 70: 257-269

FLAMM RE, HARRIS-WARRICK RM (1986) Aminergic modulation in lobster stomatogastric ganglion II. Target neurons of dopamine, octopamine and serotonin within the pyloric circuit. Am Physiol Soc 55: 866-881

FLOREY E, RATHMAYER M (1978) The effect of octopamine and other amines on the heart and on neuromuscular transmission in decapod crustaceans: further evidence for a role as neurohormone. Comp Bioch Physiol 61C: 229-237

FUTUYMA DJ (1979) Evolutionary Biology. Sunderland, MA: Sinauer Associates, Inc.

HARRIS-WARRICK RM, JOHNSON BR, PECK JH, KLOPPENBURG P, AYALI A, SKARBINSKI J (1998) Distributed effects of dopamine modulation in the crustacean pyloric network. Ann NY Acad Sci 860: 155-167

HAYE PH, OJEDA FP (1998) Metabolic and behavioral alterations in the crab Hemigrapsus crenulatus (MilneEdwards 1837) induced by its acanthocephalan parasite Profilicollis antarcticus (Zdzitowiecki 1985). J Exp Mar Biol Ecol 228: 73-82

HELLUY S, HOLMES JC (1990) Serotonin, octopamine, and the clinging behavior induced by the parasite Polymorphus paradoxus (Acanthocephala) in Gammarus lacustris (Crustacea). Can J Zool 68: 12141220

HELLUY S, THOMAS F (2003) Effects of Microphallus papillorobustus (Platyhelminthes: Trematoda) on serotonergic immunoreactivity and neuronal architecture in the brain of Gamarus insensibilis (Crustacean: Amphipoda). Proc R Soc Lon B. 270: $563-568$

HOLMES JC, BETHEL WM (1972) Behavioral aspects of parasite transmission. Zool J Linn Soc Suppl 1: 123149

HOWARD RD, MINCHELLA DJ (1990). Parasitism and mate competition. Oikos 58: 120-121

HUBER R (2005) Amines and motivated behaviors: a simpler systems approach to complex behavioral phenomena. J Comp Physiol 191A: 231-239.

KRAVITZ EA, GLUSMAN S, HARRIS-WARRICK RM, LIVINGSTONE MS, SCHWARZ T, GOY MF (1980) Amines and a peptide as neurohormones in lobsters: actions on neuromuscular preparations and preliminary behavioral studies. J Exp Biol 89: 159-175

KRAVITZ EA (1988) Hormonal control of behavior: amines and the biasing of behavioral output in lobsters. Sci 241: 1775-1781

KRAVITZ EA (2000) Serotonin and aggression: insights gained from a lobster model system and speculations on the role of amine neurons in a complex behavior. Comp Biochem Physiol 186A: 221-238

KUMAR AM, KUMAR M, DEEPIKA K, FERNÁNDEZ JB, EISDORFER C (1990) A modified HPLC technique for simultaneous measurement of 5hydroxytryptamine and 5-hydroxyindoleacetic acid in cerebrospinal fluid, platelet and plasma. Life Sci 47(19): 1751-1759

LAFFERTY KD, MORRIS AK (1996) Altered behavior of parasitized killifish increases susceptibility to predation by bird final host. Ecol 77: 1390-1397

LATHAM ADM, POULIN R (2002) Field evidence of the impact of two acanthocephalan parasites on the mortality of three species of New Zealand shore crabs (Brachyura). Mar Biol 141: 1131-1139

LIBERSAT F, PFLUEGER H-J (2004) Monoamines and the orchestration of behavior. Biosci 54(1): 17-25
LIVINGSTONE MS, HARRIS-WARRICK RM, KRAVITZ EA (1980) Serotonin and octopamine produce opposite posture in lobsters. Sci 208: 76-79

MAYNARD BJ, DEMARTINI L, WRIGHT WG (1996) Gammarus lacustris harboring Polymorphus paradoxus show altered patterns of serotonin-like immunoreactivity. J Parasitol 82: 663-666

MILLER MW, BENSON JA, BERLIND A (1984) Excitatory effect of dopamine on the cardiac ganglia of the crabs Portunus sanguinolentus and Podophthalmus vigil. J Exp Biol 108: 97-118

MOORE J (1984a) Altered behavioral responses in intermediate host. An acanthocephalan parasite strategy. Am Nat 123: 572-577

MOORE J (1984b) Parasites that change the behaviors of their host. Sci Am 250: 82-89

MOORE J, GOTELLI NJ (1996) Evolutionary patterns of altered behavior and susceptibility in parasitized host. Evol 50: 807-819

MOORE J, GOTELLI NJ (1992) Moniliformis moniliformis increases cryptic behaviors in the cockroach Supella longipala. J Parasitol 78: 49-53

MOORE J, FREEHLING M, GOTELLI NG (1994) Altered behavior in two species of blattid cockroaches infected with Moniliformis moniliformis (Acanthocephala). J Parasitol 80: 220-223

NOGUCHI H, HAYAKAWA Y (2001) Dopamine is a key factor for the induction of egg diapause of the silkworm, Bombyx mori. Eur J Biochem 268: 774-780

OETINGER DF, NICHOL BB (1982) Developmental relationships between acanthocephalans and altered pigmentation in freshwater isopods. J Parasitol 68: 463-469.

OVERLI $\varnothing$, PÁLL M, BORG B, JOBLING M, WINBERG S (2001) Effects of Schistocephalus solidus infection on brain monoaminergic activity in female three-spined sticklebacks Gasterosteus aculeatus. Proc R Soc Lond B 268: 1411-1415

PAZTOR VM, MACMILLAN DL (1990) The action of proctolin, octopamine and serotonin on crustacean propioceptors. J Exp Biol 152: 485- 504

PÉQUÉUX A, LE BRAS P, CANN-MOISAN C, CAROFF J, SÉBERT P (2002) Polyamines, indolamines, and catecholamines in gills and haemolymph of the euryhaline crab, Eriocheir sinensis. Effects of high pressure and salinity. Crustaceana 75(3-4): 567-578

POULIN R (1994). Meta-analysis of parasite-induced behavioral changes. Anim Behav 48: 137-146

POULIN R (1995) "Adaptative" changes in the behavior of parasitized animals: A critical review. Int J Parasitol 25: $1371-1384$

RAJASHEKHAR KP, WILKENS JL (1991) Dopamine and nicotine, but not serotonin, modulate the crustacean ventilatory pattern generator. J Neurobiol 23: $680-691$

READ AF (1990) Sexual selection and the role of parasites. Trends Evol Ecol 3: 97-101

SIEGEL S, CASTELLAN J (1988) Nonparametric Statistics for the Behavioral Sciences. $2^{\text {nd }}$ ed. New York: McGraw-Hill

SEPPÄLÄ O, ANSSI KARVONEN A, TELLERVO EV (2004) Parasite-induced change in host behavior and susceptibility to predation in an eye fluke-fish interaction. Anim Behav 68: 257-263

SNEDDON LU, TAYLOR AC, HUNTINGFORD FA, WATSON DG (2000) Agonistic behavior and biogenic amines in shore crabs Carcinus maenas. J Exp Biol 203: $537-545$

SOMBATI S, HOYLE G (1984) Generation of specific behaviors in a locust by local release into neuropil of 
the natural neuromodulator octopamine. J Neurobiol 15: 481-506

TAKEDA N, TAKAODA H, SHIMIZU T, YAZAWA M, YAGI S (1991) Biogenic amine levels in the central nervous system and haemolymph of the silkworm, Bombyx mori. Comp Biochem Physiol 100C: 677-682
THOMPSON SN, KAVALIERS M (1994) Physiological bases for parasite-induced alterations of host behavior. Parasitol 109: 119-138

WALKER RJ, BROOOKS HL, HOLDEN-DYE L (1996) Evolution and overview of classical transmitter molecules and their receptors. Parasitol 113 Suppl: S3-33 